\title{
Jogos e games como meios para o desenvolvimento cognitivo: uma reflexão com foco nas metodologias ativas
}

\author{
Willian Rufato da Silva* \\ Profa. Dra. Marilene S. dos Santos Garcia**
}

\section{Resumo}

O objetivo deste estudo é analisar a origem e os conceitos relacionados aos jogos e gamificação no processo de ensino aprendizagem, cujo propósito reside no divertimento e aprendizagem ao mesmo tempo. Consideraremos os resultados de pesquisas que atestam que a gamificação promove o desenvolvimento do aluno, impactando no desenvolvimento cognitivo e estudos da inteligência emocional, fator que aprofunda a discussão em torno das metodologias e aprendizagens ativas. A metodologia empregada optou por uma análise comparativa a partir dos referenciais teóricos existentes utilizando os seguintes autores: Macgonial (2012), Goleman (2012), Bar-On (2000), Prensky (2007) e Moran (2018). A pesquisa demonstra que houve grandes avanços no que se refere a estratégias gamificadas na educação, principalmente se comparadas com as abordagens mais tradicionais, porém ainda há um grande cenário a ser explorado, principalmente no que tange às formas de imersão, raciocínios, memória e atenção no

* Mestrando do Programa Lato-sensu de Mestrado em Educação e Tecnologia da UNINTER-Paraná. Pós-Graduado em Educação Especial e inclusiva pela mesma instituição. Graduado em Letras, Português - Inglês, e respectivas literaturas pela Universidade Tuiuti do Paraná. Atualmente, é Professor de Língua inglesa em rede privada de ensino e atua como especialista responsável em Sala de Recursos Multifuncionais (tipo I) em Curitiba-PR. E-mail: willianrufato@hotmail.com

** Professora do Programa de Pós-Graduação - Mestrado em Educação e Novas Tecnologias - PPGENT - UNINTER. Com Pós-Doutorado pela PUC-SP - TIDD, com Doutorado em Letras pela Universidade de São Paulo e Mestrado pela UNICAMP. Autora dos livros: Mobilidade Tecnológica e Planejamento didático (Senac-SP) e Avaliação e Validação de projetos (Senac -SP). E-mail: marilene.g@uninter.com 
decorrer do jogo. Contudo, pode-se preliminarmente concluir que metodologias ativas, que incluem processos de gamificação e jogos, sejam estes analógicos ou digitais, cooperam no processo de aprendizagem como estímulo cognitivo e motivacional, abarcando crianças, jovens e adultos. Essas metodologias ativas devem incluir abordagem inovadora que instiga a autonomia e o aprendizado de maneira mais interativa e imersiva.

Palavras-chave: Games. Metodologias ativas. Motivação.

\section{Abstract}

The objective of this study is to analyze the origin and concepts related to the games and gamification in the learning process, whose purpose is in the fun and learning at the same time. It will be considered the results of research that attest that gamification promotes in the student's development, impacting on cognitive development and studies of emotional intelligence. The methodology chosen used a comparative analysis from the existing theoretical references using the following authors: Macgonial (2012), Goleman (2012), Bar-On (2000), Prensky (2007) and Moran (2018). The research shows that there are great advances in gamification strategies in education, especially if compared to the traditional approaches, but there is still a large scenario to be explored, especially with regard to forms of immersion and reasoning, memory and attention in the course of the game. However, it may be preliminary to conclude that new methodologies, which include gamification and games processes, whether analog or digital, cooperate in the learning process as a cognitive and motivational stimulus addressing children, young people and adults. These active methodologies should include innovative approach that instigates autonomy and learning in an interactive and immersive way.

Key-words: Games. Active methodologies. Motivation.

\section{Resumen}

El objectivo de este estudio es analizar el origen y los conceptos relacionados con los juegos y la gamificación en el proceso de aprendizaje, cuyo propósito es la diversión y el aprendizaje al mismo tiempo. Se considerarán los resultados de la investigación que atestiguan que la gamificación promueve el desarrollo del estudiante, impactando en el desarrollo cognitivo y estudios de inteligencia emocional. La metodología elegida utilizó un análisis comparativo de las referencias teóricas existentes utilizando los siguientes autores: Macgonial (2012), Goleman (2012), Bar-On (2000), Prensky (2007) y Moran (2018). La investigación muestra que hay grandes avances en las estrategias de gamificación en educación, especialmente si 
se compara con los enfoques tradicionales, pero aún hay un gran escenario por explorar, especialmente con respecto a las formas de inmersión y razonamiento, la memoria y la atención en el curso de el juego. Sin embargo, puede ser preliminar concluir que las nuevas metodologías, que incluyen los procesos de gamificación y juegos, ya sean analógicos o digitales, cooperan en el proceso de aprendizaje como un estímulo cognitivo y de motivación dirigido a niños, jóvenes y adultos. Estas metodologías activas deben incluir un enfoque innovador que promueva la autonomía y el aprendizaje de una manera interactiva e inmersiva.

Palabras clave: Juegos. Metodologías activas. Motivación.

\section{Breve histórico sobre o jogo}

Escavações arqueológicas encontraram diversos jogos que datam de centenas de anos antes de Cristo, mas a ideia de jogo pode ser relacionada à memória coletiva da educação familiar, que se relaciona com processos de interação entre pais e filhos, com as primeiras brincadeiras com os bebês, ou mesmo observando-se as crianças quando brincam de pega-pega ou esconde-esconde. Tais jogos sempre existiram na humanidade como forma de educar o corpo e a mente para sobrevivência e também para o lazer.

Os jogos de tabuleiro vêm desde o início das civilizações de que se tem notícia. Estes podiam ser jogos feitos para a realeza, como o Jogo Real de Ur, ou simplesmente para todos, como os jogos de mancala. ${ }^{1}$ Os jogos de cartas cresceram durante a Idade Média e se popularizam até o presente. Atualmente, os jogos eletrônicos dominam o mercado.

A palavra Jogo tem sua origem no latim, "Jocus". Seu significado é o de brincadeira e divertimento. Jogos são atividades estruturadas, praticadas com fins recreativos a partir de regras. Em alguns casos, são reconhecidos como instrumentos educacionais, por meio dos quais visam transmitir uma mensagem aos jogadores (vencedores e perdedores). Os jogos envolvem distração, relaxamento, mas, no entanto, podem demandar expressão de ideias e

Os jogos de mancala também são denominados jogos de tabuleiro, são jogados em todas as regiões do mundo, e trazem regras gerais que orientam a forma de jogá-los. 
emoções envolvendo muita estimulação mental ou física. Muitos deles ajudam a desenvolver habilidades práticas, servem como uma forma de exercícios ou realizam um papel educativo, com processos de simulação e interação psicológica, quando o jogador assume e faz a imersão em diferentes mundos.

Jogos são disputados contra adversários, porém, o que os diferencia em competições são as características desses adversários, que podem estar na figura de outro jogador ou na forma de uma simulação de quem interage e atua como jogador, isso é possível no caso de jogos digitais, com inteligência artificial, uso de programas de computador ou realidade virtual.

\section{Jogos e inteligência emocional}

Os jogos propiciam o exercício da inteligência emocional, fator que se tornou relevante na cultura do trabalho e das relações sociais, comprovando ser um poderoso modelo para a educação na forma de aprendizado social. A inteligência emocional é reconhecida como ingrediente fundamental para o desenvolvimento da liderança vista como um agente ativo para o enfrentamento da vida.

Segundo o modelo de Goleman (2012), a estrutura da inteligência emocional se dá pelo quarteto formado pelos seguintes elementos: autoconsciência, autogestão, consciência social e gerenciamento de relacionamentos. Goleman nos traz de forma empírica a reflexão acerca do estudo de Bar-On, pois é uma das provas mais convincentes de que a inteligência emocional reside em áreas cerebrais distintas das que operam o $\mathrm{QI},{ }^{2}$ fato que tem evidenciado a base cerebral da inteligência emocional: a partir da neuroimagem e estudos de lesões. Ao desenvolver seu estudo sobre o estado cerebral certo para a função, o referido estudioso, nos elucida que o autodomínio requer autoconsciência mais autorregulação, e caracteriza esses elementos como essenciais na inteligência emocional.

Ainda sobre tais estudos, pode-se aprofundar mais o entendimento a respeito das funções e estados pessoais quando o indiví-

2 Quociente de inteligência. 
duo opera alguma atividade, no caso específico nos reportamos ao jogo. Esse aspecto está relacionado à eficácia pessoal, pois temos de estar no melhor estado interior para a tarefa em questão. Por exemplo, se o indivíduo estiver de bom humor, em estado de satisfação, ele pode tornar-se mais criativo, com melhores estratégias para a resolução de problemas, pois atinge uma melhor flexibilidade mental, resultando em tomadas de decisões mais eficientes. Por sua vez, estando de mau humor, havendo posturas negativas, nas quais incluem uma tendência para atuar de forma menos discriminativa na distinção de argumentos frágeis e sólidos, ou tomar decisões apressadamente, prestando pouca atenção nos detalhes exigidos numa tarefa, produz-se erros por falta de concentração.

Com relação ao nível cognitivo, os indivíduos tendem a ser mais pessimistas do que otimistas, portanto, mais predispostos a desistir mais rapidamente quando as coisas dão errado ou não andam bem, conforme se esperava. Um indivíduo mal-humorado pode ser influenciado pelas dificuldades enfrentadas no jogo, podendo desistir dele e quando trabalhando em equipe, pode reduzir a eficácia dessa equipe. Assim, pode-se inferir que quando um jogo flui ou as atividades gamificadas são superadas em seus desafios, o nível de satisfação tende a subir, melhorando aspectos que podem abrir margem para boas aprendizagens.

Goleman ressalta que atualmente a criatividade no cérebro não é simplesmente esquerdo - direito, também é acima - abaixo ou seja o cérebro como um todo pode gerar habilidades criativas. Por meio de seus estudos de imagem, ele pormenoriza o autodomínio sendo que a autorregulação da emoção e dos impulsos depende grandemente da interação entre o córtex pré-frontal, centro executivo do cérebro, e os centros emocionais do mesencéfalo, particularmente o circuito que converge para a amígdala. A amígdala é um ponto de disparo da angústia, da raiva, do impulso, do medo, ou seja, a interação entre essas duas áreas neurais cria, segundo o autor, uma rodovia neural que, quando em equilíbrio, é a base para o autodomínio. 
Assim sendo, o aprendizado por meio de games motiva os alunos a aprenderem de forma independente, sem as instruções necessariamente feitas pelo professor. Os games são úteis para iniciantes, para que possam avançar a aprendizagem de forma autônoma e intuitiva, embora o cérebro sempre estará em atividade, pois incentiva os usuários a rever o que eles aprenderam, bem como, reaprender o que eles esqueceram.

Normalmente, por exemplo, em atividades gamificadas, desenhadas para um aplicativo, vão aumentando gradativamente em termos de dificuldade, porém o grande diferencial de estudar pelos dispositivos móveis está na possibilidade de imersão em qualquer lugar e a qualquer momento, permitindo ao usuário ser protagonista do seu aprendizado, principalmente, pelo exercício que move suas escolhas, pelo que delibera estudar, interagir com outros indivíduos, buscar novas estratégias para vencer desafios.

Prensky (2007) pondera que a ordem dos fatores no design deveria ser: motivação, reflexão, individualização, criação e, apenas no final, o conteúdo. Dessa forma, educadores precisam praticar e colocar o envolvimento antes do conteúdo quando planejam seus cursos de forma gamificada. Para o autor, a jogabilidade (gameplay) - é um elemento capaz de manter o jogador constantemente desafiado e motivado, de forma que deveria ter prioridade ao se planejar materiais educacionais.

\section{Gamificação}

A gamificação, termo que vem do idioma inglês, gamification, é a prática de aplicar mecânicas de jogos em diversas áreas, como negócios, saúde e vida social. O principal objetivo é aumentar o engajamento e despertar a curiosidade dos usuários. Além dos desafios propostos nos jogos, na gamificação as recompensas também são itens fundamentais para o sucesso. Essa característica em atividades educacionais tem recebido críticas dos que defendem recursos de engajamento inteligente do aprendiz, sem que este seja movido a estímulos dessa natureza. Contudo, para o ensino de línguas a re- 
compensa tem sido vista como um modo lúdico para se conquistar objetivos de aprendizagem (GARCIA, 2017).

A prática da gamificação tem avançado social e educacionalmente, pois vem sendo inserida em vários aplicativos e livros, combinando práticas analógicas e digitais.

Assim, para Mattar (2014, p. 43):

Os designers de games utilizam métodos eficientes para fazer as pessoas aprender e gostar de aprender, sendo, por isso, teóricos práticos do aprendizado. Precisamos então prestar atenção a bons jogos de computador e videogames, e aplicarmos os princípios de aprendizado que eles envolvem.

Segundo Jane Macgonial (2012), os games se tornaram fundamentais e populares no processo de ensino aprendizagem, logo gamificar uma experiência produz resultados benéficos porque o cérebro humano gosta de resolver desafios, competir, obter respostas rápidas e ter incentivo, além de outras experiências positivas que os jogos provêm.

A gamificação pode ser pensada a partir de pelo menos duas perspectivas: a) como forma de persuasão, estimulando a competição, tendo um sistema de pontuação, de recompensa, de premiação, o que do ponto de vista da educação reforça uma perspectiva epistemológica empirista; b) como construção colaborativa e cooperativa, instigada por desafios, missões, descobertas, empoderamento em grupo, o que do ponto de vista da educação nos leva à perspectiva epistemológica interacionista.

\section{Relações do jogo com a cognição, prazer, admira- ção e afinidades}

Macgonial (2012), em sua obra, A realidade em jogo, nos traz à luz que os jogos ativam a dopamina no nosso cérebro, proporcionando prazer. Por ser uma ferramenta que traz resultados, tanto que os games são muito aplicados na área de marketing, eles são utilizados para alavancar a venda de produtos, sendo a ativação emocional extrema a principal razão pela qual os atuais jogos de computador 
e videogames de maior sucesso são tão viciantes e suscetíveis a mudar o nosso humor. Quando estamos em um estado concentrado de envolvimento otimista, temos, subitamente, mais probabilidades biológicas para pensar positivamente, estabelecer conexões sociais e desenvolver forças pessoais.

A partir do exposto, faz-se necessário conceituar Fiero, que é uma palavra italiana, a qual significa "orgulho" e tem sido adotada por criadores de jogos para descrever um estágio emocional para o qual não se tem uma boa palavra que possa traduzi-la em outras línguas.

Fiero é o que sentimos depois de triunfarmos sobre a adversidade. $\mathrm{O}$ fato de que virtualmente todos os seres humanos expressam o fiero da mesma forma física é um sinal claro de que está atrelado a nossas emoções mais primitivas. Segundo os pesquisadores do Center for Interdisciplinary Brain Sciences Research, da Universidade de Stanford- EUA, o fiero é a emoção responsável pelo desejo de sair da caverna e conquistar o mundo. É o desejo por desafios que possamos superar, batalhas que possamos vencer e perigos que possamos exterminar.

Estudos têm demonstrado que o otimismo torna mais provável a possibilidade de procurarmos apoio social e desenvolvermos relacionamentos mais sólidos. Ao sentirmos uma forte sensação de ação e motivação, atraímos pessoas para as nossas vidas, para exemplificar, quando convidamos amigos e familiares a jogar conosco, seja pessoalmente ou on-line, o jogador tem oportunidades de jogar seus jogos favoritos diante de plateias, podendo tornar-se épico, pois supera em muito o mediano, especialmente em tamanho, escala e intensidade levando à admiração.

A habilidade de sentir admiração na forma de calafrios, estremecidos ou engasgos serve como um tipo de radar emocional para detectar uma atividade que tenha sentido. Sempre que admiramos algo, sabemos que estamos diante de uma fonte potencial de sentido. Descobrimos uma oportunidade real de estar a serviço, de criar conexões, de contribuir para uma causa maior (MACGONIAL, 2012, p. 107). 
Admiração é um grande chamado para a ação coletiva. Os seres humanos herdam tradições ancestrais e se tornam épicos, pois notavelmente estão mais acessíveis para um número maior de pessoas todos os dias.

McGonigal (2011) afirma que as pessoas preferem jogos de cooperação, verificando que se olharmos para o que acontece nos jogos, constatamos que a maioria das pessoas não quer competir, mas, sim, trabalhar com os seus amigos para atingir um objetivo comum. De acordo com a autora, se os jogadores estão dispostos a realizar desafios que envolvem obstáculos muitas vezes desnecessários, os jogos têm a capacidade de mobilizar, então podem ser utilizados como tecnologia de transformação social.

Os jogos ou atividades gamificadas são um convite para viver experiências diversificadas, que envolvem uma série de ações inclusivas aos socializadores e àquelas que se estruturam por afinidades. Mendonça (2018), a partir de Gee (2008), apud Mendonça, afirma que:

...os espaços de afinidades ou affinity spaces podem proporcionar uma aprendizagem chamada pelo autor de life changing learning. Por meio dos comentários e das experiências dos alunos, podemos supor que estes espaços de criação digital podem se aproximar do que o autor chama de espaços de afinidades e, em alguns casos, promover uma aprendizagem que faça sentido e que encoraje o aluno a continuar buscando o estudo e o conhecimento (MENDONÇA, 2018, p. 124).

Segundo Ryan e Deci (2000) existem, na sua teoria da autodeterminação, vários tipos de motivação extrínseca e intrínseca que se constituem de um modo contínuo e não separado. Segundo mostra a Figura 1: Motivação intrínseca e motivação extrínseca. 
Figura 1: Motivação intrínseca e motivação extrínseca.

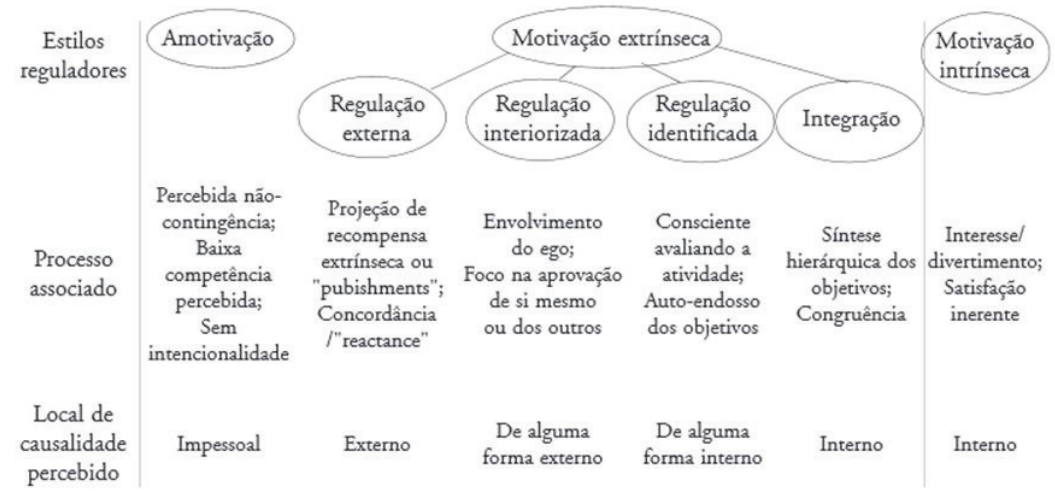

Fonte: Baseado na taxonomia da motivação humana (RYAN e DECI, 2000).

Para a teoria da autodeterminação, a motivação intrínseca baseia-se em três características que, quando encontradas num sistema gamificado, podem tornar a experiência significativa: competência (habilidade e sentido de realização para resolver tarefas), autonomia (liberdade para escolher o caminho) e vínculo (sentido de significado ou propósito atribuído à tarefa).

A grande proposta da Metodologia Ativa é aperfeiçoar a autonomia individual do aluno, desenvolvendo-o como um todo, para que ele seja capaz de compreender aspectos cognitivos, socioeconômicos, afetivos, políticos e culturais.

\section{Metodologias ativas e os jogos}

As metodologias ativas emergem a partir de alguns importantes pressupostos, que sustentam que o aluno é um ser ativo em busca de sua aprendizagem. O primeiro pressuposto é da autonomia, das escolhas e tomadas de decisão. O segundo pressuposto é de que o professor deve assumir a função de orientador que tenha relevância como curador ao desenvolver projetos com alunos. $\mathrm{O}$ terceiro deles é promover uma relação com a realidade. Oferecer jogos e atividades gamificadas intensificam o perfil autônomo, pois 
são simuladas situações desafiadoras, opções para a escolha de recursos, bem como, são dadas oportunidades de reflexão e crítica sobre aspectos da realidade.

Segundo Moran (2018), as metodologias ativas são pontos de partida para avançar para processos mais avançados de reflexão, de integração cognitiva, de generalização, de reelaboração de novas práticas. Para o autor:

A diversidade de téncinas pode ser útil, se bem equilibrada e adaptada entre o individual e o coletivo. Cada abordagem - problemas, projetos, design, jogos, narrativas - tem importância, mas não pode ser superdimensionada como única [...] Na educação formal, há muitas combinações possíveis, com variações imensas na aplicação e resultados, que vamos experimentando de forma dinâmica e constante, reavaliando-as de acordo com a conveniência para obter os resultados desejados (MORAN, 2018, p. 12 e 13).

O professor norte-americano Mel Silberman utilizou o pensamento do filósofo chinês Confúcio para delimitar o que seria uma metodologia ativa de aprendizagem: "O que en ouço, en esqueço; o que en vejo, eu lembro; o que en faço, eu compreendo". Ele desdobra o pensamento para dentro da sala de aula: apenas ver e ouvir um conteúdo de maneira passiva não é o suficiente para absorvê-lo; o conteúdo e as competências devem ser discutidos e experimentados para chegar ao ponto em que o aluno, com os seus pares, possa falar sobre o assunto dominado e até lecioná-lo na educação do século XXI.

\section{Considerações finais}

Pelo levantamento da literatura referente a jogos e a processos de gamificação, pode-se concluir que estes podem ser importantes meios para o desenvolvimento cognitivo, principalmente quando associados à perspectiva das metodologias ativas.

A motivação gerada por atividades gamificadas educacionais impulsiona a produtividade e o desempenho, despertando o interesse pela aprendizagem. Dessa forma, o crescimento da motivação para o progresso do desenvolvimento cultural manifesta-se pela 
possibilidade de atender às expectativas mais humanas e libertadoras para o processo de ensino e aprendizagem.

As estratégias educacionais gamificadas tornam-se importantes recursos da metodologia ativa, uma vez que são uma concepção educacional que coloca os estudantes como agentes protagonistas de seu aprendizado. Por meio desta, o estímulo à crítica e reflexão devem ser incentivados pelo professor que conduz a aula, mas o centro desse processo é, de fato, o próprio aluno que se engaja e participa dela.

O desafio volta-se também para o educador, curador dos conhecimentos, facilitador e mediador desse processo, que trata de aproveitar a aprendizagem do aluno jogador para outras metas relevantes para o seu desenvolvimento educativo.

O design de jogos não é apenas um ofício tecnológico ou passatempo. Esse deve ser considerado como uma forma atual de pensar, liderar e conquistar uma mudança real ao protagonizarmos melhores alternativas imersivas para a realidade por meio de um maior envolvimento efetivo dos sujeitos nos processos de ensino e de aprendizagem, favorecendo o desenvolvimento da autonomia, da autoria, da colaboração, da cooperação, bem como instigando a solução de problemas e o pensamento crítico além de ampliar as possibilidades da construção de sentidos.

Portanto, com um alto poder positivo de envolvimento educacional, espera-se que mais trabalhos futuros possam enriquecer a comunidade científica que se atém a esse aspecto, no sentido de ampliar as possibilidades de tais benefícios para os processos de ensino e aprendizagem.

\section{Referências}

BAR-ON, R. Emotional and Social Intelligence: Insights from the Emotional Quotient Inventory. In: R. Bar-On \& J. D. A. Parker (Orgs.). The Handbook of Emotional Intelligence. San Francisco: Jossey-Bass, 2000. 
BAR-ON, R., \& HANDLEY, R. The Emotional Quotient 360 (EQ-360): A Multirater Assessment for Emotional Intelligence. Toronto, Canadá: Multi-Health Systems, 1997.

GARCIA, Marilene S. S. Mobilidade Tecnológica e Planejamento Didático. São Paulo: Editora Senac-SP, 2017.

GOLEMAN, Daniel O cérebro e a inteligência emocional: novas perspectivas. Rio de Janeiro: Editora Objetiva, 2012.

McGONIGAL, J. A realidade em jogo: Por que os games nos tornam melhores e como eles podem mudar o mundo. Rio de Janeiro: Ed. Best Seller, 2012.

MENDONÇA, Helena A. Construção de jogos e uso de realidade aumentada em espaços de criação digital na educação básica. In: Metodologias ativas para uma educação inovadora. Porto Alegre: Penso, 2018.

MORAN, José Metodologias ativas para uma aprendizagem mais profunda. In: Metodologias ativas para uma educação inovadora. Porto Alegre: Penso, 2018.

PRENSKY, M. Digital game-basedlearning: practical ideas for the application of digital game-based learning. St. Paul, MN: Paragon House, 2007.

RYAN, Richard M. e DECI, Edward L. Intrinsic and Extrinsic Motivations: Classic Definitions and New Directions. In: Contemporary Educational Psychology, 2000. Disponível em http://mmrg.pbworks.com/f/Ryan,+Deci+00.pdf, consultado em 17/07/2017.

SILBERMAN, M. Aprendizaje activo. 101 estrategias para enseñar cualquier tema. Buenos Aires: Troquel, 1998.

Submetido em: 19-3-2018

Aceito em: 27-3-2018 